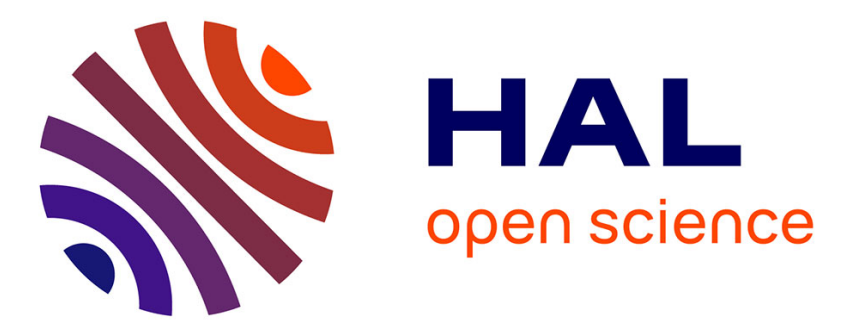

\title{
Double-clad hollow-core photonic crystal fiber for nonlinear optical imaging
}

F Delahaye, Frédéric Gérôme, F Amrani, A Unterhuber, K Vasko, B Debord, M Andreana, F Benabid

\section{To cite this version:}

F Delahaye, Frédéric Gérôme, F Amrani, A Unterhuber, K Vasko, et al.. Double-clad hollow-core photonic crystal fiber for nonlinear optical imaging. CLEO: Conference on Lasers and Electro-Optics 2021 US, May 2021, San José (virtual), United States. pp.AF2Q.2. hal-03285287

\section{HAL Id: hal-03285287 \\ https://hal.science/hal-03285287}

Submitted on 21 Jul 2021

HAL is a multi-disciplinary open access archive for the deposit and dissemination of scientific research documents, whether they are published or not. The documents may come from teaching and research institutions in France or abroad, or from public or private research centers.
L'archive ouverte pluridisciplinaire HAL, est destinée au dépôt et à la diffusion de documents scientifiques de niveau recherche, publiés ou non, émanant des établissements d'enseignement et de recherche français ou étrangers, des laboratoires publics ou privés. 


\title{
Double-clad hollow-core photonic crystal fiber for nonlinear optical imaging
}

\author{
F. Delahaye ${ }^{1}$, F. Gérôme ${ }^{1,2}$, F. Amrani ${ }^{1,2}$, A. Unterhuber ${ }^{3}$, K. Vasko ${ }^{2}$, B. Debord ${ }^{1,2}$, M. Andreana ${ }^{3}$ and F. $^{2}$ \\ Benabid ${ }^{1,2}$ \\ ${ }^{1}$ Glophotonics S.A.S., 123 Avenue Albert Thomas, 87060 Limoges Cedex, France \\ ${ }^{2}$ GPPMM group, XLIM, CNRS-UMR 7252 Université de Limoges, 123 Avenue Albert Thomas, 87060 Limoges Cedex, France \\ ${ }^{3}$ Medical university of Vienna, 23 Spitalgasse, 1090 Wien, Austria \\ f.benabid@xlim.fr
}

\begin{abstract}
We report on simultaneous CARS and two-photon excited fluorescence imaging using tailored double-clad hypocycloid core-contour Kagome fiber optimized for broad bandwidth lowloss, high bioimaging collection efficiency and reduced bend loss sensitivity.
\end{abstract}

\section{Introduction}

Biophotonic imaging offers new opportunities for in vivo recording of morphological, molecular, metabolic and signaling information pathways at cellular level [1]. Such synergistically combined information provides understanding of disease origin at an early stage and paves the way for new diagnostics, treatment, drug efficacy testing and development for a wide range of diseases. Biophotonics imaging precisely addresses the unmet clinical needs due to the non-invasive, real-time capture of biomedical information at subcellular level, label-free or by use of exogenous markers. Specifically, nonlinear optical imaging methods, such as two-photon excited fluorescence (TPEF) [2] and coherent anti-Stokes Raman scattering (CARS) [3], are extremely powerful techniques for multimodal imaging contrast. TPEF microscopy is the most popular and universal implementation of multiphoton microscopy (MPM) to investigate dynamic interaction at a molecular level. The careful choice of these modalities integrated into a combined endoscopic approach enables sensitivity and specificity that is larger than just the sum of each part, owing to the simultaneous availability of relevant biomarkers. However, there are still some key challenges, which need to be addressed for in vivo and in situ imaging when fiber delivery over several meters might be required. The optical fiber has to simultaneously meet the technical requirements of each imaging modality especially for endoscopic configurations. TPEF and CARS require short laser pulses (usually with pulse widths shorter than $100 \mathrm{fs}$ ) for efficient signal excitation. In conventional optical fibers, short pulse propagation is affected mainly by self-phase modulation (SPM) and other nonlinear effects which broaden the spectral and temporal shape of the laser pulses and normal group-velocity dispersion (GVD) restricts an undistorted pulse propagation thus precluding an efficient signal excitation. An elegant and innovative way to address undistorted broadband and short pulse delivery is the use of low-loss optical fiber technology that guides light in a hollow-core surrounded by a two dimensional periodic cladding [4]. In particular, inhibited-coupling (IC) Kagome hollow-core (HC) photonic crystal fibers (PCFs) [5,6] have been identified as a versatile means for transporting high power ultrashort laser pulses with low losses as well as low temporal, spectral, modal pulse distortion due to negligible dispersion and optical overlap with the silica cladding. Hence, in this paper, we report on purposely designed fiber to handle the multimodalities requirement in nonlinear bioimaging. The fiber consists of IC HCPCF whose core presents a hypocycloidal contour for ultrashort pulse handing and a cladding comprises a Kagome lattice optimized for a broad bandwidth low-loss with reduced bending sensitivity and a double clad with large numerical aperture (NA) for a high collection efficiency.

2. Double-clad hollow-core inhibited-coupling fiber development

Two specific double-clad IC HCPCFs have been developed and fabricated using standard stack-and-draw process. The fibers have a hypocycloid core-contour in the range of 40-45 $\mu \mathrm{m}$ (with a negative curvature of 0.7 , see [5] for definition) surrounding by a 3 rings Kagome-latticed cladding and an air-clad as indicated in Fig. 1(a). The fibers exhibit IC guidance in a hollow-core with loss figure of $50 \mathrm{~dB} / \mathrm{km}$ between $800 \mathrm{~nm}$ to $1.1 \mu \mathrm{m}$ for MPM investigation and NA of 0.02 . The two cladding are separated by a silica ring. The ring thickness was set to $20 \mu \mathrm{m}$ for Fiber \#1, and to $6 \mu \mathrm{m}$ for Fiber \#2 in order to have different NA (0.16 for Fiber \#1, 0.24 for Fiber \#2) and assess their bioimaging collection efficiency. The reconstructed near fields (NF) of the modes inside the hollow core and the silica ring are shown in Fig. 1(d), along with the far-field when both waveguides are excited. We note that the hollow core mode NF profile remains unchanged upon fiber bending and shaking, indicating robust singlemode IC guidance. Finally, the bend loss which is a key parameter towards bioimaging has been measured. The result presented in Fig. 1(c) show that the sensitivity of curvature has been reduced compared to our previous result [7]. For example Fiber \#2 exhibits a bend loss at both useful wavelengths $(850 \mathrm{~nm}, 1000 \mathrm{~nm})$ of less than 0.1 
$\mathrm{dB} /$ turn (i.e. $0.15 \mathrm{~dB} / \mathrm{m}$ ) for a bend radius of $10 \mathrm{~cm}$. Notice that the associated polarization extinction ratio has also been improved to achieve respectively $11 \mathrm{~dB}$ and $15 \mathrm{~dB}$ at $1064 \mathrm{~nm}$ for a 3m-long piece of Fiber \#1 and Fiber \#2.

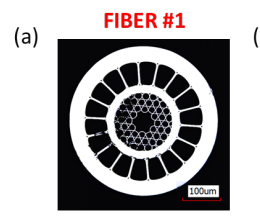

FIBER \#2

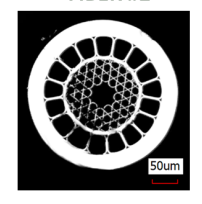

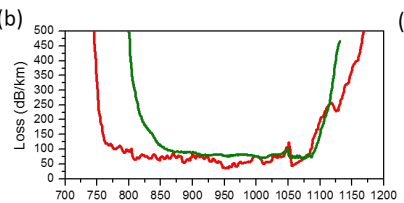

(c)

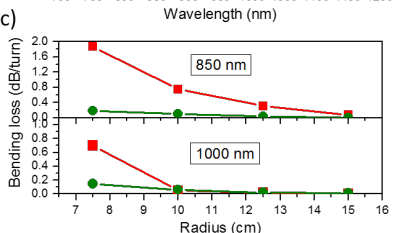

(d)
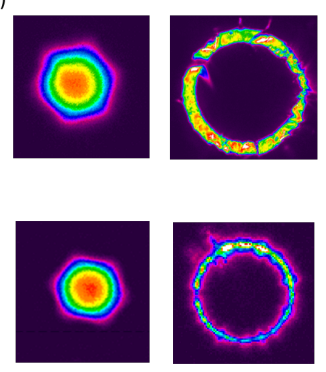
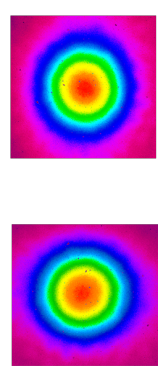

Fig. 1: (a) Optical micrograph of the cross section of the fabricated fibers, (b) Loss spectrum obtained between $700 \mathrm{~nm}$ to $1200 \mathrm{~nm}$ and (c) bend loss sensitivity at $850 \mathrm{~nm}$ and $1 \mu \mathrm{m}$ of the two fibers, (d) NF and FF recorded from the core and silica ring regions at the output of the fibers.

\section{Multimodal imaging}

The imaging performances over $3 \mathrm{~m}$ of Fiber \#1 is demonstrated by simultaneously recording hyperspectral CARS and TPEG images of a test sample consisting of green dragon polystyrene (GDP) microsphere of $\sim 15 \mu \mathrm{m}$ diameter (FSDG009, Bangs Laboratories, Inc.) immersed in water. The simplified experimental setup for the demonstration is shown in Fig. 2(a) [8]. By changing the temporal overlap between the pump (800 nm) and Stokes (1050 nm) beams a fast tuning of the Raman frequency can be obtained matching the Raman frequency of the $\mathrm{CH}$ bonds present in the polystyrene microsphere. Simultaneously TPEF excitation of green fluorophore was achieved by wavelength mixing of the pump and Stokes beams. TPEF and CARS signals were simultaneously recorded by two photomultiplier tubes by spectral discrimination. Fig. 2(b) and (c) show the TPEF and CARS images of the green dragon microsphere at the perfect time overlap between pump and Stokes. Fig. 2(d) shows the spectral contrast on TPEF and CARS channels which consist of a projection of a 240 images dataset recorded along the spectral dimension corresponding to a time delay range between the pump and Stokes pulses of $\sim 6 \mathrm{ps}$. Future work entails the use of Fiber \#2 and demonstration of imaging when the fiber is in motion.
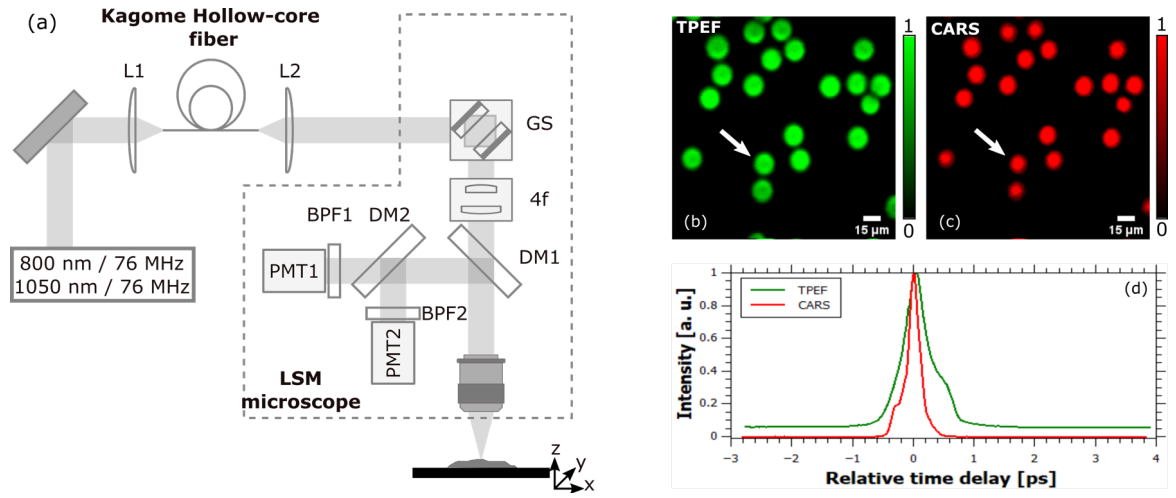

Fig. 2: (a) Experimental setup used for excitation and collection of TPEF and CARS images of the GDP beads. (b) TPEF image where the contrast is based on GDP fluorophore. (c) CARS image where the contrast is based on the CH bond of polystyrene. The images are $256 \times 256$ pixels, $6.4 \mu \mathrm{m}$ pixel dwell time. (d) Spectral profile of the bead is indicated by white arrow. The pump and Stokes power were at the sample 20 $\mathrm{mW}$ and $10 \mathrm{~mW}$, respectively.

\section{Conclusion}

Double-clad IC HCPCFs have been optimized to demonstrate broad bandwidth low-loss, large NA and reduced bend loss sensitivity. The imaging capability of those fibers was tested by simultaneously imaging TPEF and CARS signals in the $\mathrm{CH}$ stretching vibrational region from a mixture of GDP beads. The obtained image quality is comparable to those achieved with previous demonstrations in free space laser scanning microscope setting, suggesting that this approach could pave the way for use in an endoscope.

[1] W. R. Zipfel et al., Nat. Biotechnol., vol. 21, no. 11, pp. 1369 (2003)

[2] W. Denk et al., Science, vol. 248, no. 4951, pp. 73 (1990)

[3] A. Zumbusch et al., Phys. Rev. Lett., vol. 82, no. 20, p. 4142 (1999)

[4] M. Andreana et al., Optics Letters, vol. 44, no. 7, p. 1588 (2019)
[5] B Debord et al., MDPI - fiber, papier review, 7, 16 (2019)

[6] M. Maurel et al., Optics Letters, Vol. 43, Issue 7, pp. 1598 (2018)

[7] F. Delahaye et al., CLEO, paper JTh2A.97 (2018)

[8] M. Andreana et al, JBO, vol. 22, no. 9, p. 091517 (2017) 